\title{
Systemic diagnostic analysis of the social and economic situation in Russia
}

\author{
Sergey V. Kucheryavenko ${ }^{1, a}$, Konstantin A. Chekhovskikh ${ }^{1}$, Olga V. Ulyanova ${ }^{1}$ \\ ${ }^{1}$ Yurga Institute of Technology affiliated branch of National Research Tomsk Polytechnic University, 652050 Leningradskaya Street 26, \\ Yurga, Russia
}

\begin{abstract}
The paper presents one of possible options for the analysis of the socio-economic situation in Russia today under the conditions of growing dynamism, diversity and uncertainty of changes in global and domestic economy. The study implements the main provisions of the authors' methodology of a diagnostic analysis of complex human-dimension systems based on general theory of systems and a systemic organizational approach. Different aspects of diagnosis of objects and systems are analyzed from the standpoint of improving a new methodology for system-diagnostic analysis in different areas of research and practice. The authors formulate objectives, criteria and principles for reforming the society; they determine the basic vectors of focus for eliminating the main socio-economic pathologies.
\end{abstract}

\section{Introduction}

Today's international and domestic economy is characterized by rising dynamism, diversity and uncertainty of changes which are taking place. Economic life proves that growing information flows require an appropriate reaction as well as ability to find solutions quickly and efficiently. Macroeconomic parameters which are to be set and regulated by appropriate state institutions (Government, Central Bank and others) often do not meet challenges of contemporary international and domestic economy. Numerous economic research teams have different opinions on how to make a diagnosis and what are the ways to recover from a long crisis. A system crisis needs and calls for a systemic analysis. That is why it is important to develop a special methodology for studying supercomplex economic systems which could make up the basis for modern management technologies. Systemic diagnostic analysis is this very methodology $[1,2]$.

Diagnosing a real condition of an object alongside with internal changes, which are taking place, has always been important in different spheres of human activity. It is clear that any area for diagnosing, as well as the diagnostics as it is, has its unique specific features. But the diagnostics can also be characterized by some common traits and laws as far as, on the one hand, diagnostics can be applied to any purposeful activity and, on the other hand, the objects under diagnosis are organized according to the systemic principle. [3]. The key point is that a precise diagnosis is an essential precondition for forecasting, designing, modeling and other types of social and economic responses at all social levels [4].

Nobody doubts that any human activity has an adaptive research nature. A. Toynbee described a system "Challenge - Response" which means that a person has to find proper solutions to meet every day natural, social and political challenges. This is the only possibility for humankind to survive. It is the research activity that determines the choice of survival ways and forms. It implies identifying the object, processes and phenomena which people have to deal with. The deeper the perception of the nature and specifics of a challenge, the more successful the human activity is. Thus any real life situation can be considered a diagnosable object, validity of the diagnosis is the basis not only for short tactic success but also for development of long term forecast and life strategies. In this view, a diagnostic analysis serves for recognizing the nature of a challenge, which is essential for adaptation, survival, productive activity [1].

\section{Methodology}

The diagram below (Figure 1) shows two important facts.

1. A diagnosis is a necessary condition of any human activity, its first stage, which is responsible for finding the only acceptable solution leading to the survival of the system.

2. The subject of the diagnostic analysis plays the key role. Substitution of the real conditions of the object life by fictional ones as well as errors in determining

\footnotetext{
${ }^{a}$ Corresponding author: serg_kuch60@mail.ru
} 
essential features, qualities and properties of the object lead to its destruction (Figure 1).

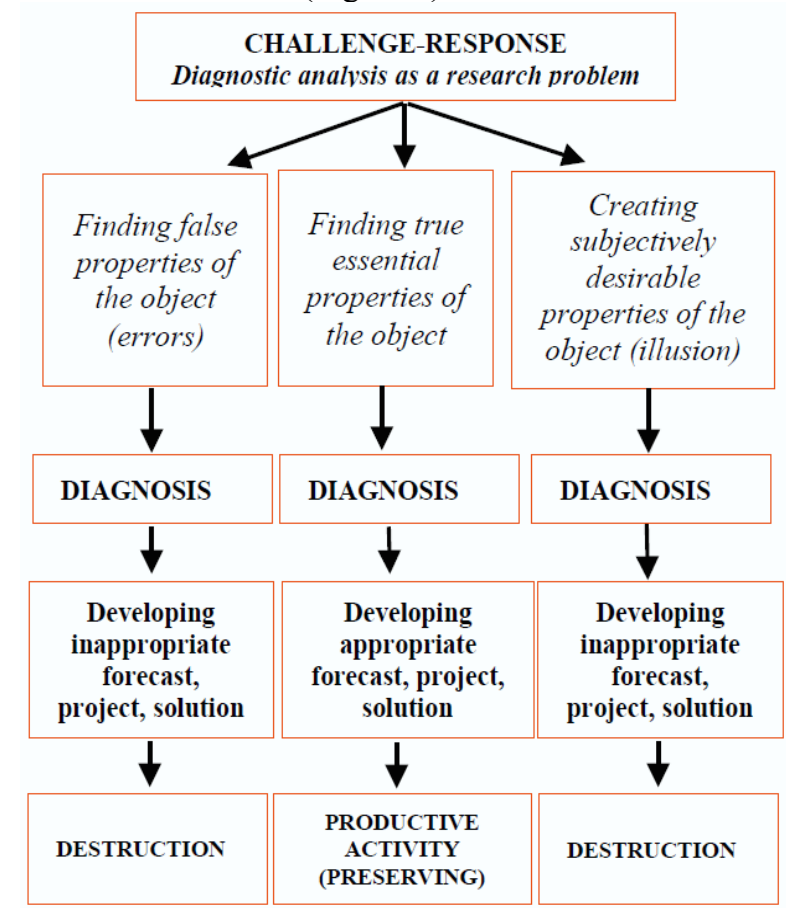

Fig. 1. The process and possible outcomes of the diagnostic analysis

\section{Results and discussion}

Farther, let us consider how the system diagnostics can be applied to an analysis of social and economic processes in today's Russia. Based on a systemdiagnostic study [5], we will develop and concretize certain provisions of systemic diagnosis of socioeconomic situation in Russia implemented there, bearing in mind that economic study alone is of little use in this situation because of its one-sidedness. On the one hand, it happens because the terminology and methods of modern economic theory are congested with an analysis of specifically economic aspects to the detriment of research into indigenous, system-economic causes and factors. On the other hand, the economic effects are extremely interconnected and interdependent with psychological, political, socio-cultural, environmental, demographic phenomena, especially when it comes to reforming an unstable system. Therefore, a purely economic analysis of the situation in the country can have only a secondary importance. As noted by L.I. Abalkin, "Of fundamental importance for the economic theory is not only consideration of its object - the economy - as an integrated system, but also its analysis as a part of more complex social systems or socioecological and sociobiological supersystems" [6]. Thus, constructive analysis of explicit and latent problems of Russian society should be based on integration of system and economic methodology, taking into account the interaction of the whole complex of social, economic and spiritual factors.

Principles of the systemic and organizational approach, developed in a number of papers [4, 7] and tested in a diagnostic study of a socio-economic situation in Russia [5] are the most effective to deal with such social and diagnostic tasks. From the perspective of system-dialectical concepts developed in this work, the system is regarded as an organized whole, ensuring the preservation of its stability, operation and development on the basis of resolution of conflicts in the specified environmental conditions.

The most complete, thorough and comprehensive analysis of a set of socio-economic contradictions which caused a protracted systemic crisis in Russia has been given in the fundamental monograph [8]. Based on this analysis, the authors of the systemic diagnostic study have formulated objectives for reforming the society to resolve these contradictions. In particular, it is assumed that the main goal of all reforms should be the formation of comprehensively healthy society including demographic, environmental, economic, political and military aspects. This purpose is precisely the systemic one in contrast to more specific tasks repeatedly put forward such as creating a market, democracy, implementing privatization, increasing GDP, reducing poverty, forming the middle class, and so on. The inadequacy of the latest tasks is proved by life itself, by the fact that a "wild" market and unreasoned privatization prompted the country to the brink of economic, social and demographic catastrophe; democracy has degenerated into chaos, anarchy and shameless pervasive corruption. Collateral and debt privatization led to a huge income gap between the rich and the poor (more than 40 times). The rich are getting richer and the poor - poorer. As noted by Academician Nikolai Petrakov, "... all the economic "shocks" fall on the middle class: real estate market taxes, compulsory motor insurance, deliberate ruble strengthening by the Central Bank so that people get out of dollars. The middle class suffers the most from these developments as the rich will buy off and the poor have nothing"[8]. All these phenomena have relevance not by themselves but in particular well-defined forms and in complex combinations with other forms including the opposite ones.

However, the stated purpose of reforms is largely abstract and it is necessary to formulate criteria of compliance of the reforms to this purpose reflecting the systemic specifics of the society. The basic axioms of such criteria is as follows. Firstly, it is mutual support of organismic system elements. Secondly, it is the central position of an individual as the main active component of any social system. Thirdly, it is transformation of the reform program into a "human dimension" scale of all the decisions taken. Fourth, it is a transition from a human neglected way of society development to human saving and human developing evolution. Fifth, it is relying on the natural course of events during the reforms correcting them by supplementing developments. Sixth, it is the use of not only (and not so much) economic, but also social resources and reform criteria for resolving society economic problems. The success of large-scale socio-economic reforms by Ludwig Erhard in Germany and Deng Xiaoping in China suggested the use of the above axioms in their reform efforts. 
In view of the above, several criteria for successful reforms have been outlined. The first criterion is clarity, accessibility and unambiguous meaning and content of reforms for each person, not just for experts and specialists. Accordingly, the second criterion is the need to involve everyone in the best of their ability and opportunities into the planning and functioning of the socio-economic system. The third criterion for a successful course of reform, as already mentioned, is not only economic, but also moral, psychological, demographic, environmental improvement of society. This, in turn, implies restoring social justice, humanizing living and working conditions, developing and growing the so-called "middle class", reducing a social distance between the rich and the poor, giving each active person an opportunity to find a good use of their forces and abilities, greening production, increasing efficiency of the productive forces, re-orienting the economy onto the development of high-tech industries and emerging technologies, and so on [5]. These criteria are formulated in general terms, and their set is far from being exhausted. However, they are fundamental, because without progress on the parameters fixed by them it is pointless to argue about the real achievements of the reforms.

Formulated objectives and criteria for the reform of Russian society allowed going directly to making systemic diagnosis to the socio-economic organism and discussing ways to overcome its fundamental flaws. The methodological base of system-diagnostic analysis consists of the principles of the systematic and organizational approach, reflecting the most fundamental conditions of the organizational optimization of complex systems, namely: focusing system actions on resolving the current conflict; complexity; the allocation of the main (decisive) elements; organizational flexibility; phased development [1].

The principle of a focused action reflects the main mechanism of system activity and organizational optimization of complex objects. To resolve its current contradictions and, as a result, to preserve function and development stability, the system acts as a focusing lens, i.e. concentrates and directs potential of its components, links, resources, activities and actual environment to achieving functional results resolving these contradictions. Greater focus of the system organizational parameters on achieving functional results stipulates a more significant effect of its action to resolve current conflicts. Delving into the essence of the contradictions between the enormous natural and human potential of Russia and extremely low standard and quality of people's life, the main attention was paid to the factors and causes of focusing of the system on false aims. Here are the main aspects of the inconsistency of socio-economic system of today's Russia and the principle of focusing the action on resolution of current conflicts. First, it is the absence of a clear, deep understanding of state and society development goals which appeal to the majority of the population. Second, it is the destruction of the planning mechanism - a single, centralized management of the country. Third, it is the lack of large-scale national projects of modernization of the country. Fourth, it is inefficiency of the vertical hierarchy of the government.

It should be further noted that the absence of a state ideology is enshrined in the Russian Constitution, and therefore, there is no clearly articulated aims of state development. It deprives the country of the possibility to focus the efforts of the whole society to solve urgent problems and thus run an effective mechanism systemic action. Only a clear system of goals uniting Russia's desire to take a worthy place in the international community and expressing the fundamental interests of Russians is able to unite the country into a whole to overcome the prolonged systemic crisis and build a sustainable, dynamic state: "... a real revival of the country's life potential is possible on the basis of social justice, collectivism and strengthening great power principles"[5].

One of the competitive advantages is the geopolitical position of Russia in the north of Eurasia, which enables the implementation of a number of large-scale modernization projects of global significance. "The shortest and cheapest routes linking the two fastestgrowing economic regions - Western European and Pacific - go through Russia. This is not only a source of capital but also the opportunity to use the achievements of civilization that links the "Eurasian bridge" [9].

Prominent representatives of Russian science make concrete proposals for the preparation and implementation of such events. In particular, N.N. Moiseyev says that "... the formation of large-scale programs is an important duty of the State" [10].

According to international historical experience, one of the most important factors of political power and the social and integrating role of the state is establishing control over the activities of the mass media, especially television and the Internet. This control should not involve total censorship and should not limit the freedom of the media in fulfilling its socially useful functions. The role of the government is to create a powerful barrier to the cult of violence, cruelty, cynicism, individualism, universal mindless consumerism, and other extremely dangerous stereotypes of primitive mass culture. To do this, it is necessary to focus the activities of mass media on the formation of patriotism, high morality, culture, humanitarian and human ideals.

Another principle of the system-organizational approach to the diagnostic study of socio-economic situation in Russia is the principle of complexity, which is aimed at the formation of the system as a completed structure, which elements are integrated in order to achieve a common goal. This principle requires accounting features and interaction of all the components or aspects of the system, determination of the balance of the system conditions with the environment, and overall impact on the system in its transformation [5]. Diagnosing organizational defects in the socio-economic structure of the country in terms of violation of the complexity principle, the destruction of the whole economic complex, which happened due to the collapse of the Soviet Union, and the absence of real convergence of the planned and market methods of enterprise were found. 
The first of the mentioned pathologies creates insurmountable difficulties for businesses that lost traditional sales markets and / or their reliable and responsible suppliers. For the country as a whole, this situation means the loss of a significant part of production capacity, maintaining a high level of unemployment, professional and intellectual degradation of a large part of the active population. Therefore, one of the most important tasks of the state in the economy is to restore to a qualitatively new basis of the structural economic complex. Implementation of this ambitious task can only be based on the recovery of the planned management of socio-economic development of the country.

The real facts of both global and Russian economy suggests that purely market economy society leads not to prosperity but to the growing chain of catastrophes [11]. Therefore, a planned-market economy is required, because the planning system in a daunting economy of Russia is ineffective without market, and the market without a planned mechanism is shortsighted and destructive. Only together, in complementarity and mutual coordination, they are able to regulate the socioeconomic processes successfully. The planned mechanism ensures the integrity and coordination of the focused approach to the management of economic complex, implementation of deterministic laws of economics and global trends (e.g., science and technology, mitigation of market crisis fluctuations). The market mechanism is responsible for stochastic processes in the economy; it provides economy with flexibility, adaptability to the peculiar conditions of regions, areas, renovation of production incentives for producers and competition. This combination of two opposite ways of economy is proved by one of the developers of an integrated socio-economic model for the developing by biological laws of post-industrial society of the third millennium, A.I. Filimonov [12].

The principle of identification of the main link is that to operate successfully in complex, multifaceted situation when it is impossible to carry out all the desired actions at the same time, it is necessary to identify key facilities and the efforts that most effectively lead to the targeted goals. The main links should be the ones that affect the condition and the possibilities of the other links and are thus have the greatest impact on the whole of the system. The main types of the main links are "weak" links (elements, ties, processes), limiting the overall effectiveness of the system, the "leading" links that can provide the functional effect on a number of other units, as well as control units and resource providing links which ensure viability of the system.

The principle of organizational flexibility (agility) should be taken into account in the changing conditions of functioning and development of the system. The antipode of dynamism is organizational rigidity, which leads to a drastic drop in efficiency of the system when internal and external conditions change. Diagnosing the causes of failure in the reform, we point out, in accordance with the principle under consideration, the phenomenon of «homo soveticus», ignored by some reformers but still an extremely stable unique human species formed as a result of the socialist experiment. The consequence was the lack of a sophisticated sociocultural and social policy reforms" [13].

One aspect of the principle of organizational dynamism is the mobility of self-organizational system reactions to dysfunctions of any localization. In the context of almost total impunity and irresponsibility of the government officials at all levels of government, the use of this aspect would make any deviation from the norm or breach economically disadvantageous to the offender. E.G. Vinogray noted that "because dysfunctional deviations are detrimental to the interests of specific executors and divisions, they immediately detect such deviations and demand their elimination" [7].

Moreover, the principle of a phased development of the system allows diagnosing it in terms of optimal allocation of the effort in time in the process of qualitative transformation of the system. Violation of this principle has led in due time to the failure of the socialist experiment that began in the country which was unprepared for it. In contrast, in a number of northern European countries, where this principle was not violated, the socialist ideals were implemented.

Returning to inertial factors, aggravation of which, in our opinion, can be explained by theories of a "third wave" by Alvin Toffler [14], according to which all the world development is divided into three waves: the preindustrial, industrial and postindustrial. What is happening in the world has recently been defined by the conflict of last two waves - industrial and postindustrial ones, because humankind in entering the information age. Accordingly, there is a conflict of elite groups of the second and third waves, accompanied by a collapse of social values, attitudes, and lifestyle.

Diagnostic analysis allows identifying a set of priority measures for the operational improvement of the economy and the creation of preconditions for the future fundamental reforms. First, we are talking about improving the legal framework governing the tripartite relationship between the owners, management and the employees. The peculiarity of the Russian capitalism is an opportunity for owners and managers of enterprises to ravage the companies under their control. Financial fraud, bribing officials and false companies are widespread.

The situation is exacerbated by the fact that, according to I.V. Bestuzhev-Lada, in conditions of high unemployment and chaos in the legal sphere of the economy, hired workers are deprived of their rights, unprotected and forced to endure the situation, while the state has kept itself aloof from these problems [15]. Therefore, one of the most important functions of the state in modern conditions should be the re-establishment of a civilized legal framework of organizational and financial relations in enterprises and organizations, and strict monitoring of its implementation. State bodies, trade unions, public authorities, and employees of enterprises should participate in such monitoring.

Another measure is to reorganize the tax system to stimulate domestic production. The tax system should be simplified, and that is being done now. However, the main direction of its reformation is tax differentiation. 
The real-producing sector of the economy with respect to taxes should be reduced and the bank trading and broking sector taxes should be increased so as to create real incentives for the inflow of capital into the sphere of production.

Restructuring of debts of enterprises, in particular, debts to the budget, is of great importance. Unfortunately, the majority of the Russian companies cannot solve the problem of debt recovery. Therefore, special bodies should be created to help the resuscitation of the most promising companies.

One of the most pressing problems in the country is still that of poverty, despite the fact that the number of billionaires in today's Russia is second only to the United States and Germany. The reforms do not comply with the inner world of a person who lives in a constant state of stress, and therefore dies of cardiovascular diseases. How can the problem of poverty be solved? First, it is necessary to amend the Income Tax Act immediately, to make a progressive scale with a strict control, as it is done in the civilized world. Calculations show that if you increase the taxation of the group of the richest Russians only by $14 \%$, it will solve the poverty problem completely, because only 7-8 billion dollars are required for this. At the same time, the taxation of all persons who receive incomes below the subsistence minimum should be cancelled. Secondly, it is necessary to introduce reasonable property taxes, taxing its lower rate, but at the market price. The third proposal is to use natural resource rents. It is necessary to withdraw the excess profits, which is extra income some businesses have from natural resources - oil, gas, forest, fish and other resources.

\section{Conclusion}

Summarizing we would like note that in order to overcome crisis Russia must assess the country's resources and competitive advantages, which it may offer to the international markets. Based on these estimates, it is necessary to develop a strategy for efficient use of these resources and continue implementing it. First, it is necessary to displace imported products from the domestic market thus stimulating import substitution (as it is being done in the Russian automotive industry) due to the devaluation of the ruble.

Investing in training highly skilled professionals has good prospects [16]. The competitive advantage of Russia is the ability to produce a wide range of products at a price significantly below the world prices. According to many experts, Russia needs to compete with the developed countries not so much on its own market, but on the markets of the third countries. It is necessary to optimize the return of borrowed funds, the dynamics of growth rates and, most importantly, stop the degradation of the country's intellectual capital.

Such are the immediate tasks of the reforms in the socio-economic sphere, the solution of which would improve the country, create conditions for the further organizational, financial, technological and structural modernization of the economy, progress in the social and spiritual spheres.

The delivered schematic diagnosis of major socioeconomic pathologies of the country and the directions of its reformation are aimed at enhancing the development of system projects of Russia's withdrawal from the crisis that would transform Russia into a united, holistic, dynamic organism. Achieving this aim is the only real shield against the economic and political genocide, taking place in the third world countries that were not able to ensure their integrity, competitiveness, economic security and political independence.

\section{References}

1. S.V. Kucherjavenko, A.N. Bystrov, Diagnosticheskij analiz kak metodologija poznanija slozhnyh system (2012)

2. K.A. Chekhovskikh, S.V. Kucheryavenko, Vestnik TGU, 301, 71-73 (2007)

3. Hrsg. von H. Hempfling, C. Burri, Diagnostische und operative Arthroskopie aller Gelenke (1991)

4. F. Heylighen, Cognitive Systems Research, 38, 50$59(2016)$

5. E.G. Vinograj, E.A. Ploskonosova, Socialnopoliticheskie $\mathrm{i}$ duhovnye processy $\mathrm{v}$ sovremennoj Rossii, 1, 26-39 (2002)

6. L.I. Abalkin, Voprosy filosofii, 8, 3-7 (1995)

7. E.G. Vinograj, Sistemno-dialekticheskij podhod: teorija i metodologija (2014)

8. Put v XXI vek: strategicheskie problemy i perspektivy rossijskoj jekonomiki (1999)

9. N.E. Petrakov, Svobodnaja mysl XXI, 11, 15-22 (2005)

10. N.N. Moiseev, Kak daleko do zavtrashnego dnja: svobodnye razmyshlenija (2002)

11. I. Jeffries, Economic developments in contemporary Russia (2011)

12. A.I. Filimonov, Sistemnye issledovanija. Metodologicheskie problemy. Ezhegodnik 1998 (1999)

13. Bolshunov, V. Lisin, A. Tihonovskij, Izvestija, (30.04.1999)

14. E. Toffler, Tretja volna (1999)

15. I.V. Bestuzhev-Lada, Rossija nakanune XXI veka. 1904-2004. Ot kolossa k kollapsu i obratno (1997)

16. M. A. Suzdalova, E. V. Politsinskaya, A. V. Sushko, Procedia, 206, 394-398 (2015) 